\title{
Efficacy of Nivolumab for Head and Neck Cancer Patients with Primary Sites and Histological Subtypes Excluded from the CheckMate-I4I Trial
}

This article was published in the following Dove Press journal: Cancer Management and Research

Yasuyoshi Sato ID
Naoki Fukuda
Xiaofei Wang
Tetsuya Urasaki
Akihiro Ohmoto'
Kenji Nakano'
Mayu Yunokawa ID
Makiko Ono'
Yukiko Sato iD ${ }^{2}$
Hiroki Mitani
Junichi Tomomatsu (D)
Shunji Takahashi'
'Department of Medical Oncology,
Cancer Institute Hospital of Japanese
Foundation for Cancer Research, Tokyo
I35-8550, Japan; ${ }^{2}$ Pathology, Cancer
Institute Hospital of Japanese Foundation
for Cancer Research, Tokyo I35-8550,
Japan; ${ }^{3}$ Head and Neck Oncology, Cancer
Institute Hospital of Japanese Foundation
for Cancer Research, Tokyo I35-8550,
Japan

Background: In the CheckMate-141 trial, nivolumab conferred a survival benefit in patients with recurrent or metastatic refractory squamous cell carcinoma (SCC) head and neck cancer (HNC). Here, we examined the efficacy of nivolumab in patients with histological subtypes or primary sites of HNC not included in the CheckMate-141 trial.

Methods: This was a retrospective analysis of data collected prospectively from 97 patients who were treated with nivolumab for recurrent or metastatic HNC at our institution. The patients were assigned to three groups based on HNC primary site: 1) oral cavity, pharynx, and larynx, which were included in CheckMate-141 $(\mathrm{n}=68), 2)$ nasopharynx (excluded in CheckMate-141, $\mathrm{n}=7$ ) and 3) other primary sites excluded in CheckMate-141 ( $\mathrm{n}=22)$ and assigned to two groups according to histological subtype: 1) SCC (included in CheckMate$141, \mathrm{n}=83$ ) and 2) non-SCC (all sites excluded in CheckMate-141, $\mathrm{n}=14$ ). Survival outcomes and nivolumab treatment response were compared between the primary site and histological subgroups.

Results: The median number of nivolumab treatments was 7 cycles (range, 1-53 cycles) and the median follow-up time was 9.1 months (range, 0.66-33.0 months). There were no significant differences in response rates between the three primary site subgroups (CheckMate-141 sites 22\%, nasopharynx 43\%, others $18 \%$; $=0$ ) or the two histological subtype subgroups (SCC 25\%, non-SCC 7\%, p=0). Similarly, overall survival and progression-free survival were comparable for patients stratified by primary site or histological subtype.

Conclusion: No significant difference in response rates or survival outcomes was detected between nivolumab-treated HNC patients with primary sites and histological subtypes that were included versus excluded in the CheckMate-141 trial. These data provide a potential rationale for nivolumab therapy for all HNC patients in clinical practice.

Keywords: head and neck cancer, nivolumab, PD-1, immunotherapy, immune checkpoint inhibitor, CheckMate-141

\section{Introduction}

Blockade of immune checkpoints, such as interactions between cytotoxic T-lymphocyte antigen-4 and its ligands CD80/CD86, and between programmed death-1 (PD-1) and its ligand PD-L1, have shown promise for the treatment of various types of cancer. ${ }^{1,2}$ In the Phase 3 CheckMate-141 trial, a comparison between the investigator's choice of therapy and nivolumab, an anti-human PD-1 monoclonal antibody, demonstrated that nivolumab significantly extended the
Correspondence: Junichi Tomomatsu Cancer Research, 3-8-3I Ariake, KotoKu, Tokyo I35-8550, Japan

Tel $+8|35200|||$

Fax $+8|335200| 4 \mid$

Email junichi.tomomatsu@jfcr.or.jp 
overall survival (OS) of patients with recurrent or metastatic head and neck cancer (HNC) who had received platinum-based chemotherapy and were ineligible for local treatment. ${ }^{3}$ Based on this result, nivolumab was approved for the treatment of recurrent or metastatic HNC by the Japanese Ministry of Health, Labour and Welfare (MHLW) in March 2017.

However, the inclusion criteria for CheckMate-141 were restricted to patients with squamous cell carcinoma (SCC) of the oropharynx, hypopharynx, larynx, and oral cavity and it remains unknown whether nivolumab may be beneficial for patients with other histological subtypes of $\mathrm{HNC}$, such as adenoid cystic carcinoma, or with other primary tumor sites, such as the nasopharynx. A Phase 2 trial of nivolumab in 44 patients with nasopharyngeal cancer (NCI-9742) reported survival outcomes that were comparable to historic results. ${ }^{4}$ However, little is known about the efficacy of nivolumab for patients with HNC of other subtypes or primary sites.

The present study aimed to compare the efficacy of nivolumab in an independent cohort of patients with $\mathrm{HNC}$ primary sites and histological subtypes that were included versus excluded from the CheckMate-141 trial.

\section{Patients and Methods}

\section{Patients}

We retrospectively analyzed prospectively collected data from 97 consecutive patients with recurrent or metastatic HNC who began treatment with nivolumab at our institution between May 2017 and December 2019. The database included the following patient characteristics: age, sex, smoking status (current, former, or never smoker), Eastern Cooperative Oncology Group performance status, location of the primary tumor, histological diagnosis, recurrent or metastatic status, and the number of previous systemic therapies. For data analysis, the 97 patients were assigned to three groups based on the location of the primary tumor: 1) oropharynx, hypopharynx, larynx, and oral cavity (CheckMate-141-included sites, hereafter referred to as CM141-PS), 2) nasopharynx (CheckMate141 excluded) and 3) other primary sites (CheckMate-141 excluded) and they were assigned to two groups based on the histological diagnosis: 1) SCC (CheckMate-141 included [CM141-HSS]) or 2) non-SCC (CheckMate-141 excluded).

Nivolumab was administered at a dose of $3 \mathrm{mg} / \mathrm{kg}$ body weight every 2 weeks from May 2017 to mid-
September 2018 and then administered at a fixed dose of $240 \mathrm{mg}$ every 2 weeks from mid-September 2018 to March 2020 (data cutoff for the present study), according to the change in guidelines approved by the Japanese MHLW. Nivolumab treatment continued until unacceptable adverse effects occurred or the disease progressed. Nivolumab was continued beyond disease progression if the physician considered that it was providing clinical benefit. Because the data were reported anonymously, the requirement for informed consent was waived. The study was approved by the Institutional Review Board of the Cancer Institute Hospital.

\section{Statistical Analysis}

All patient characteristics were compared using Fisher's exact test, with the exception of age, which was compared using one-way ANOVA. OS and progression-free survival (PFS) rates were estimated using the Kaplan-Meier method and the Log rank test. Data were censored on March 31, 2020. Patients who were lost to follow-up were censored at the date of last contact or follow-up. OS was calculated from the date of nivolumab initiation to the date of death from any cause. Patients who were alive on March 31, 2020, were censored for OS analysis. PFS was calculated from the date of nivolumab initiation to the date of disease progression or death from any cause. Tumor response was evaluated according to the Response Evaluation Criteria in Solid Tumors, version 1.1 based on computed tomography findings. The best overall response was assessed as complete response (CR), partial response (PR), stable disease (SD), or progressive disease (PD). ${ }^{5}$ The response rate (RR) corresponded to the sum of the CR and $P R$ rates and the disease control rate (DCR) to the sum of the $\mathrm{CR}, \mathrm{PR}$, and $\mathrm{SD}$ rates.

\section{Results}

\section{Patient Characteristics}

The characteristics of the 97 patients stratified by the primary tumor site and histological subtype are shown in Tables 1 and 2, respectively. The 97-patient cohort comprised 75 men and 22 women with a median age of 60.7 years; the median observation time was 9.1 months (range, 0.66-33.0 months) after initiation of nivolumab therapy. The median number of nivolumab infusions was 7 cycles (range, 1-53 cycles). Of the 97 patients, 68 (70\%) had CM141-PS, 7 (7\%) had nasopharyngeal cancer, and 22 (23\%) had HNC of other primary sites (parapharyngeal space, maxillary sinus, 
Table I Characteristics of Patients Stratified by HNC Primary Site

\begin{tabular}{|c|c|c|c|c|}
\hline & CMI4|-PS $(N=68)$ & Nasopharynx $(\mathbf{N}=7)$ & Others $(\mathrm{N}=22)$ & $\boldsymbol{P}$ \\
\hline Age (year) & & & & \\
\hline Median (range) & $64.0(32-82)$ & $51.7(46-59)$ & $59.7(30-77)$ & 0.17 \\
\hline Male sex, n (\%) & $59(87)$ & $5(7 I)$ & II (50) & 0.0015 \\
\hline Smoking, n (\%) & & & & 0.0090 \\
\hline Current & $34(50)$ & $3(43)$ & $3(14)$ & \\
\hline Former & $22(32)$ & $3(43)$ & $8(36)$ & \\
\hline Never & $12(18)$ & I (I4) & $10(45)$ & \\
\hline Unknown & $0(0)$ & $0(0)$ & $\mathrm{I}(5)$ & \\
\hline ECOG performance status & & & & 0.62 \\
\hline 0 & $31(46)$ & $5(7 I)$ & $9(4 I)$ & \\
\hline I & $35(5 I)$ & $2(29)$ & $12(55)$ & \\
\hline 2 & $2(3)$ & $0(0)$ & $\mathrm{I}(5)$ & \\
\hline Location of primary tumor, $\mathrm{n}(\%)$ & & & & - \\
\hline Larynx & $12(18)$ & - & - & \\
\hline Oral cavity & $18(26)$ & - & - & \\
\hline Hypopharynx & $19(28)$ & - & - & \\
\hline Oropharynx & $19(28)$ & - & - & \\
\hline Nasopharynx & - & $7(100)$ & - & \\
\hline Parapharyngeal space & - & - & I (5) & \\
\hline Maxillary sinus & - & - & $9(4 I)$ & \\
\hline Ethmoidal sinus & - & - & $2(9)$ & \\
\hline Orbit & - & - & $2(9)$ & \\
\hline Submaxillary gland & - & - & $3(14)$ & \\
\hline Parotid gland & - & - & $2(9)$ & \\
\hline Nasal cavity & - & - & $2(9)$ & \\
\hline Ear canal & - & - & I (5) & \\
\hline Histological diagnosis, n (\%) & & & & $<0.001$ \\
\hline Squamous cell carcinoma & $64(94)$ & $5(7 I)$ & $14(64)$ & \\
\hline Adenocarcinoma & $0(0)$ & $0(0)$ & $2(9)$ & \\
\hline Adenoid cystic carcinoma & $I(I)$ & $0(0)$ & $4(18)$ & \\
\hline Neuroendocrine cell carcinoma & $2(3)$ & $0(0)$ & $0(0)$ & \\
\hline Undifferentiated carcinoma & $0(0)$ & $2(29)$ & $0(0)$ & \\
\hline Hyalinizing clear cell carcinoma & $I(I)$ & $0(0)$ & $0(0)$ & \\
\hline Myoepithelial carcinoma ex PA & $0(0)$ & $0(0)$ & I (5) & \\
\hline Carcinoma ex PA & $0(0)$ & $0(0)$ & I (5) & \\
\hline Recurrent or metastatic, $\mathrm{n}(\%)$ & & & & 0.020 \\
\hline Recurrent & $64(94)$ & $5(7 I)$ & $17(77)$ & \\
\hline Metastatic & $4(6)$ & $2(29)$ & $5(23)$ & \\
\hline Number of previous therapies, $\mathrm{n}$ (\%) & & & & 0.033 \\
\hline 0 & $25(37)$ & $4(57)$ & $4(18)$ & \\
\hline 1 & $38(6)$ & I (I4) & $16(73)$ & \\
\hline$\geq 2$ & $5(7)$ & $2(29)$ & $2(9)$ & \\
\hline
\end{tabular}

Abbreviations: CMI4I-PS, CheckMate-I4I-included primary sites (oropharynx, hypopharynx, larynx, and oral cavity); ECOG, Eastern Cooperative Oncology Group; HNC, head and neck cancer; PA, pleomorphic adenoma.

ethmoidal sinus, orbit, submaxillary gland, parotid gland, nasal cavity, and ear canal). These three subgroups differed significantly in the sex ratio, smoking status, histological diagnosis, disease status (recurrent or metastatic), and number of previous systemic therapies (Table 1). Most patients (83, 86\%) had SCC (CM141-HSS) and only 14 (13\%) had 
Table 2 Characteristics of Patients Stratified by HNC Histological Diagnosis

\begin{tabular}{|c|c|c|c|}
\hline & $\begin{array}{l}\text { CMI4I- } \\
\text { HSS (SCC) } \\
(\mathrm{N}=83)\end{array}$ & $\begin{array}{l}\text { Non-SCC } \\
(N=14)\end{array}$ & $\mathbf{P}$ \\
\hline $\begin{array}{l}\text { Age (year) } \\
\text { Median (range) }\end{array}$ & $60.3(32-82)$ & $62.3(30-7 \mathrm{I})$ & 0.24 \\
\hline Male sex, n (\%) & $70(84)$ & $5(36)$ & $<0.001$ \\
\hline $\begin{array}{l}\text { Smoking, n (\%) } \\
\text { Current } \\
\text { Former } \\
\text { Never } \\
\text { Unknown }\end{array}$ & $\begin{array}{l}42(5 I) \\
34(4 I) \\
17(20) \\
0(0)\end{array}$ & $\begin{array}{l}4(29) \\
3(21) \\
6(43) \\
1(7)\end{array}$ & 0.026 \\
\hline $\begin{array}{l}\text { ECOG performance status } \\
0 \\
1 \\
2\end{array}$ & $\begin{array}{l}46(55) \\
48(58) \\
2(2)\end{array}$ & $\begin{array}{l}5(36) \\
8(57) \\
1(7)\end{array}$ & \\
\hline $\begin{array}{l}\text { Location of primary tumor, } \mathrm{n}(\%) \\
\text { Larynx } \\
\text { Oral cavity } \\
\text { Hypopharynx } \\
\text { Oropharynx } \\
\text { Nasopharynx } \\
\text { Others } \\
\text { Parapharyngeal space } \\
\text { Maxillary sinus } \\
\text { Ethmoidal sinus } \\
\text { Orbit } \\
\text { Submaxillary gland } \\
\text { Parotid gland } \\
\text { Nasal cavity } \\
\text { Ear canal }\end{array}$ & $\begin{array}{l}11(13) \\
17(20) \\
19(23) \\
17(20) \\
5(6) \\
14(17) \\
0(0) \\
9(11) \\
2(2) \\
0(0) \\
0(0) \\
1(1) \\
1(1) \\
1(1)\end{array}$ & $\begin{array}{l}\text { I (7) } \\
\text { I (7) } \\
0(0) \\
2(14) \\
2(14) \\
7(50) \\
\text { I (7) } \\
0(0) \\
0(0) \\
2(14) \\
3(21) \\
0(0) \\
\text { I (7) } \\
0(0)\end{array}$ & 0.02 \\
\hline $\begin{array}{l}\text { Histological diagnosis, } \mathrm{n}(\%) \\
\text { Squamous cell carcinoma (SCC) } \\
\text { Adenocarcinoma } \\
\text { Adenoid cystic carcinoma } \\
\text { Neuroendocrine cell carcinoma } \\
\text { Undifferentiated carcinoma } \\
\text { Hyalinizing clear cell carcinoma } \\
\text { Myoepithelial carcinoma ex PA } \\
\text { Carcinoma ex PA }\end{array}$ & $\begin{array}{l}83(100) \\
- \\
- \\
- \\
- \\
- \\
- \\
-\end{array}$ & $\begin{array}{l}- \\
2(14) \\
5(36) \\
2(14) \\
2(14) \\
1(7) \\
1(7) \\
1(7)\end{array}$ & - \\
\hline $\begin{array}{l}\text { Recurrent or metastatic } \\
\text { Recurrent } \\
\text { Metastatic }\end{array}$ & $\begin{array}{l}75(90) \\
8(10)\end{array}$ & $\begin{array}{l}\text { II (79) } \\
3(21)\end{array}$ & 0.20 \\
\hline $\begin{array}{l}\text { Number of previous therapies, } n(\%) \\
0 \\
1 \\
\geq 2\end{array}$ & $\begin{array}{l}32(39) \\
44(53) \\
7(8)\end{array}$ & $\begin{array}{l}\text { I (7) } \\
\text { II (79) } \\
2(14)\end{array}$ & 0.052 \\
\hline
\end{tabular}

Abbreviations: SCC, squamous cell carcinoma; CMI4I-HSS, CheckMate-14Iinclude histological subtype (SCC); ECOG, Eastern Cooperative Oncology Group; HNC, head and neck cancer; PA, pleomorphic adenoma.
non-SCC histological subtypes. There were significant differences between these two subgroups in sex ratio and location of the primary tumor (Table 2).

\section{Efficacy of Nivolumab According to HNC Primary Site}

The median OS was 12.9 months (95\% confidence interval [CI], 8.4-15.2) for patients in the CM141-PS group, 25.5 months (95\% CI, 5.3-not reached) for the nasopharynx group, and 14.1 months (95\% CI, 7.6-not reached) for the other primary site group. The 1-year OS rate were $54 \%$ (95\% CI, 41-66), 86\% (95\% CI, 33-98), and 57\% (95\% CI, 31-76), respectively. The inter-group differences were not statistically significant $(\mathrm{P}=0.17)$ (Figure $1 \mathrm{~A})$.

The median PFS was 3.6 months (95\% CI, 2.6-6.1) for patients in the CM141-PS group,14.1 months (95\% CI, 0.85-not reached) for the nasopharynx group, and 3.4 months (95\% CI, 1.4-7.1) for the other primary site group. The inter-group differences were not statistically significant $(\mathrm{P}=0.44)$ (Figure 1B). The 6-months $\mathrm{PFS}$ rate were $39 \%$ (95\% CI, 27-50), 57\% (95\% CI, 17-84), and $40 \%$ (95\% CI, 20-60), respectively.

The RR and DCR were $22 \%(\mathrm{n}=15)$ and $41 \%(\mathrm{n}=28)$, respectively, for the CM141-PS group; $43 \%(\mathrm{n}=3)$ and $57 \%$ $(\mathrm{n}=4)$, respectively, for the nasopharynx group, and $18 \%$ $(n=4)$ and $36 \%(n=8)$, respectively, for the other primary site group (Table 3 ). The inter-group differences were not significant for either the $\mathrm{RR}(\mathrm{P}=0.44)$ or $\mathrm{DCR}(\mathrm{P}=0.66)$.

Duration of nivolumab therapy until disease progression and survival time following disease progression in the nasopharynx group and the other primary site group are illustrated in bar charts (Figure 3A).

\section{Efficacy of Nivolumab According to HNC Histology}

Figure 2A shows that there were no significant differences between the median OS of the SCC (CM-141-PS) group (13.3 months, 95\% CI, 10.5-15.4) and the non-SCC group (14.3 months, 95\% CI, 4.0-not reached) $(\mathrm{P}=0.60)$. The 1-year OS rate were $56 \%$ (95\% CI, 26-77), and 57\% (95\% CI, 45-68), respectively.

Figure 2B shows that there were no significant differences between the median PFS of the SCC (CM-141-PS) group (3.9 months, 95\% CI, 2.6-6.1) and the non-SCC group (3.6 months, 95\% CI, 1.0-13.8) $(\mathrm{P}=0.82)$. The 6-months PFS rate 
A

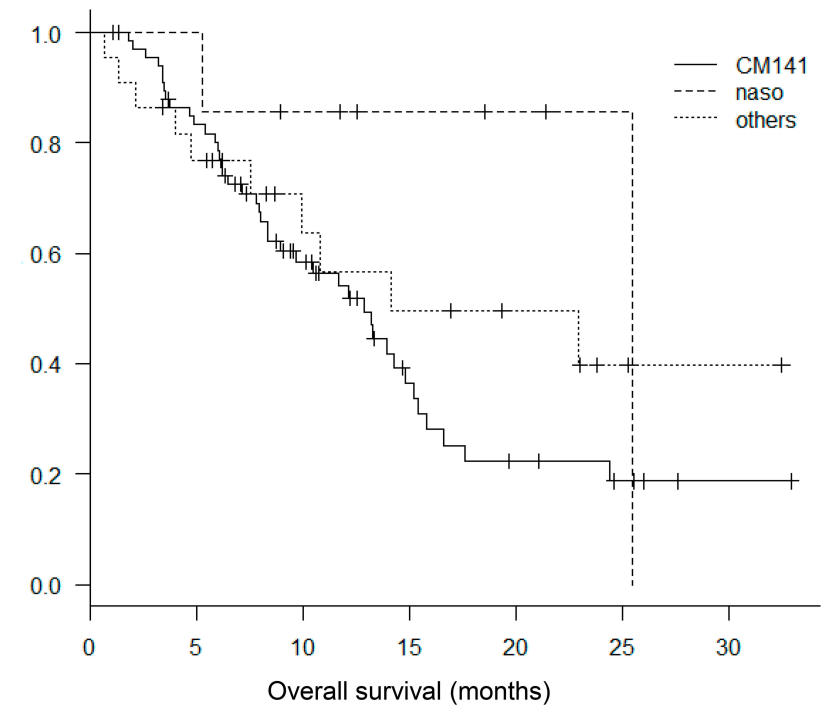

CM14168 naso 7 others 22

$\begin{array}{ccc}54 & 30 & 13 \\ 7 & 5 & 3 \\ 16 & 9 & 7\end{array}$

B

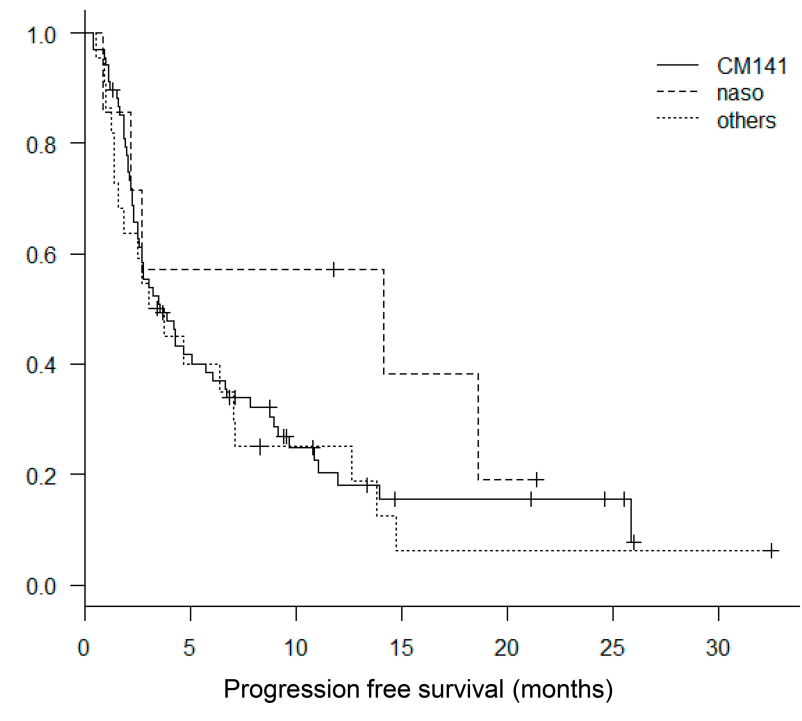

CM141 68
naso 7 $\begin{array}{cc}\text { naso } & 7 \\ \text { others } 22\end{array}$

Figure I Kaplan-Meier curves for (A) overall survival and (B) progression-free survival for patients stratified by primary site.

Abbreviations: CMI4I, CheckMate-I4I-included primary sites; naso, nasopharynx.

were $43 \%$ (95\% CI, 18-66), and 40\% (95\% CI, 29-50), respectively. The RR and DCR were $25 \%(n=21)$ and $41 \%$ $(\mathrm{n}=34)$, respectively, for the SCC (CM-141-PS) group, and 7\% $(n=1)$ and $50 \%(n=7)$, respectively, for the non-SCC group (Table 3). There were no significant differences between for either the $\mathrm{RR}(\mathrm{P}=0.18)$ or $\mathrm{DCR}(\mathrm{P}=0.57)$.

Figure $3 \mathrm{~B}$ shows duration of nivolumab therapy until disease progression and survival time following disease progression in the non-SCC group.

\section{Discussion}

In this study, we investigated the efficacy of nivolumab treatment for patients with HNC primary lesion locations or histologic subtypes that were included versus excluded in the CheckMate-141 trial. Notably, we found no significant differences between the OS, PFS, RR, and DCR in any patient group, which suggests that nivolumab may be efficacious for all HNC subgroups examined.

In the present study, the survival outcomes were comparable between nivolumab-treated patients with HNC of the nasopharynx and other primary sites excluded in the CheckMate-141 trial. Interestingly, we did detect a trend towards better OS, PFS and RR for patients with nasopharyngeal cancer compared with CheckMate-141included sites; especially, the RR of $43 \%$ (3 out of 7 ) in the nasopharynx group appears good, which could provide

Table 3 Best Overall Response Among Patient Subgroups Stratified by HNC Primary Site or Histological Diagnosis

\begin{tabular}{|c|c|c|c|c|c|c|c|}
\hline & $\begin{array}{l}\text { CMI4I-PS } \\
(\mathrm{N}=68)\end{array}$ & $\begin{array}{l}\text { Nasopharynx } \\
(\mathrm{N}=7)\end{array}$ & $\begin{array}{l}\text { Others } \\
(\mathrm{N}=22)\end{array}$ & $\boldsymbol{P}$ & $\begin{array}{l}\text { CMI4I-HSS } \\
(\mathrm{N}=83)\end{array}$ & $\begin{array}{l}\text { Non-SCC } \\
(\mathrm{N}=14)\end{array}$ & $\boldsymbol{P}$ \\
\hline CR, n (\%) & $0(0)$ & $0(0)$ & $0(0)$ & & $0(0)$ & $0(0)$ & \\
\hline PR, n (\%) & $15(22)$ & $3(43)$ & $4(18)$ & & $21(25)$ & I (7) & \\
\hline $\mathrm{SD}, \mathrm{n}(\%)$ & $13(19)$ & I (I4) & $4(18)$ & & $12(14)$ & $6(43)$ & \\
\hline PD, n (\%) & $39(57)$ & $3(43)$ & $14(64)$ & & 49 (59) & $7(50)$ & \\
\hline not evaluated, n (\%) & $I(I)$ & $0(0)$ & $0(0)$ & & $I(I)$ & $0(0)$ & \\
\hline $\mathrm{RR}, \mathrm{n}(\%)$ & $15(22)$ & $3(43)$ & $4(18)$ & 0.44 & $21(25)$ & I (7) & 0.18 \\
\hline DCR, n (\%) & $28(4 I)$ & $4(57)$ & $8(36)$ & 0.66 & $34(4 I)$ & $7(50)$ & 0.57 \\
\hline
\end{tabular}

Abbreviations: CMI4I-PS, CheckMate-I4I-included primary sites (oropharynx, hypopharynx, larynx, and oral cavity); CMI4I-HSS, CheckMate-I4I-include histological subtype (SCC); SCC, squamous cell carcinoma; CR, complete response; PR, partial response; SD, stable disease: PD, progressive disease; RR, response rate; DCR, disease control rate; HNC, head and neck cancer. 


\section{A}

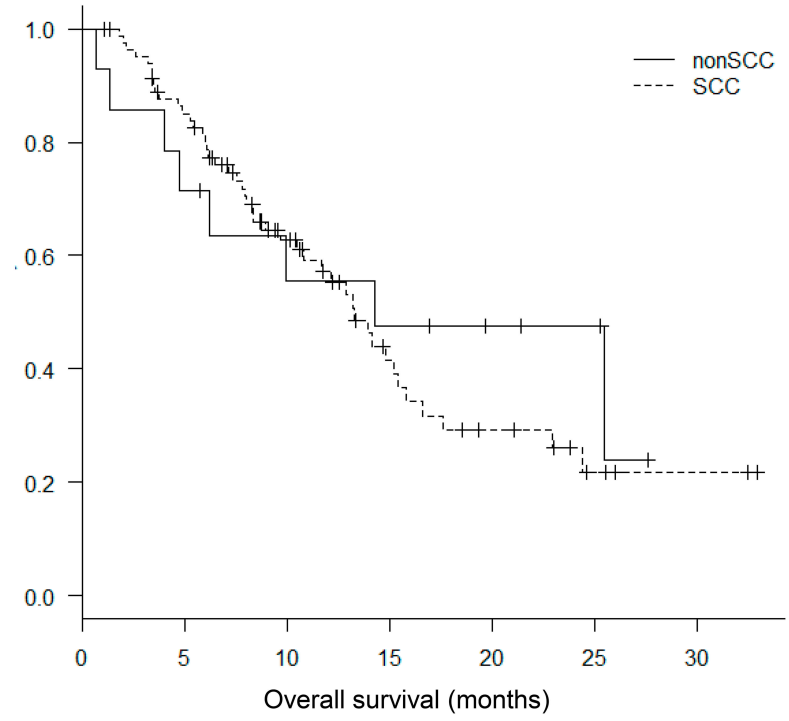

nonSCC14

SCC 83

10
67

Overall survival (months)
B

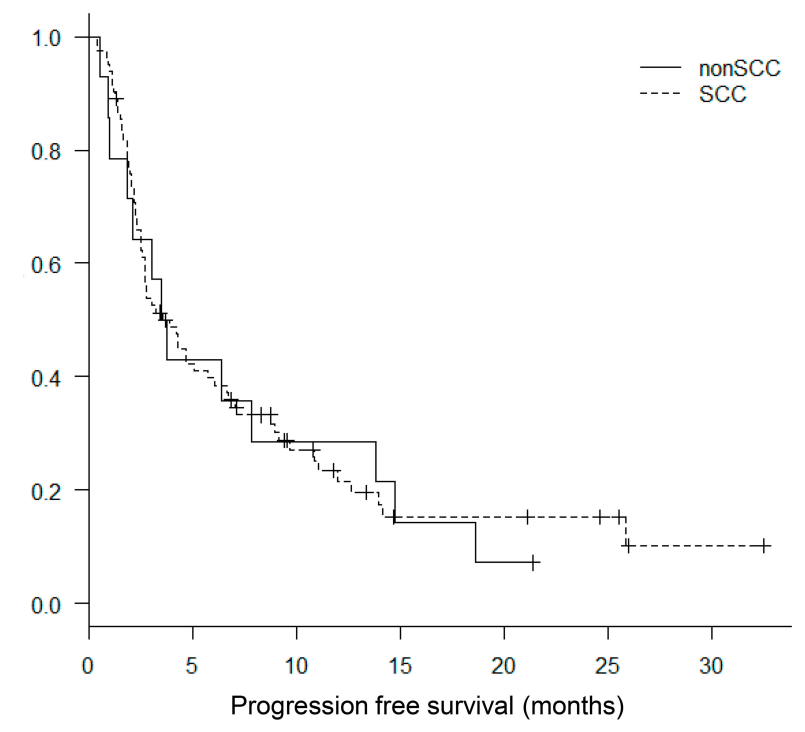

$\begin{array}{rcccccc}\text { nonSCC14 } & 6 & 4 & 2 & 1 & 0 & 0 \\ \text { SCC } 83 & 33 & 16 & 6 & 6 & 4 & 1\end{array}$

Figure 2 Kaplan-Meier curves for (A) overall survival and (B) progression-free survival for patients stratified by histological diagnosis. Abbreviation: SCC, squamous cell carcinoma (CheckMate- 14 I included).
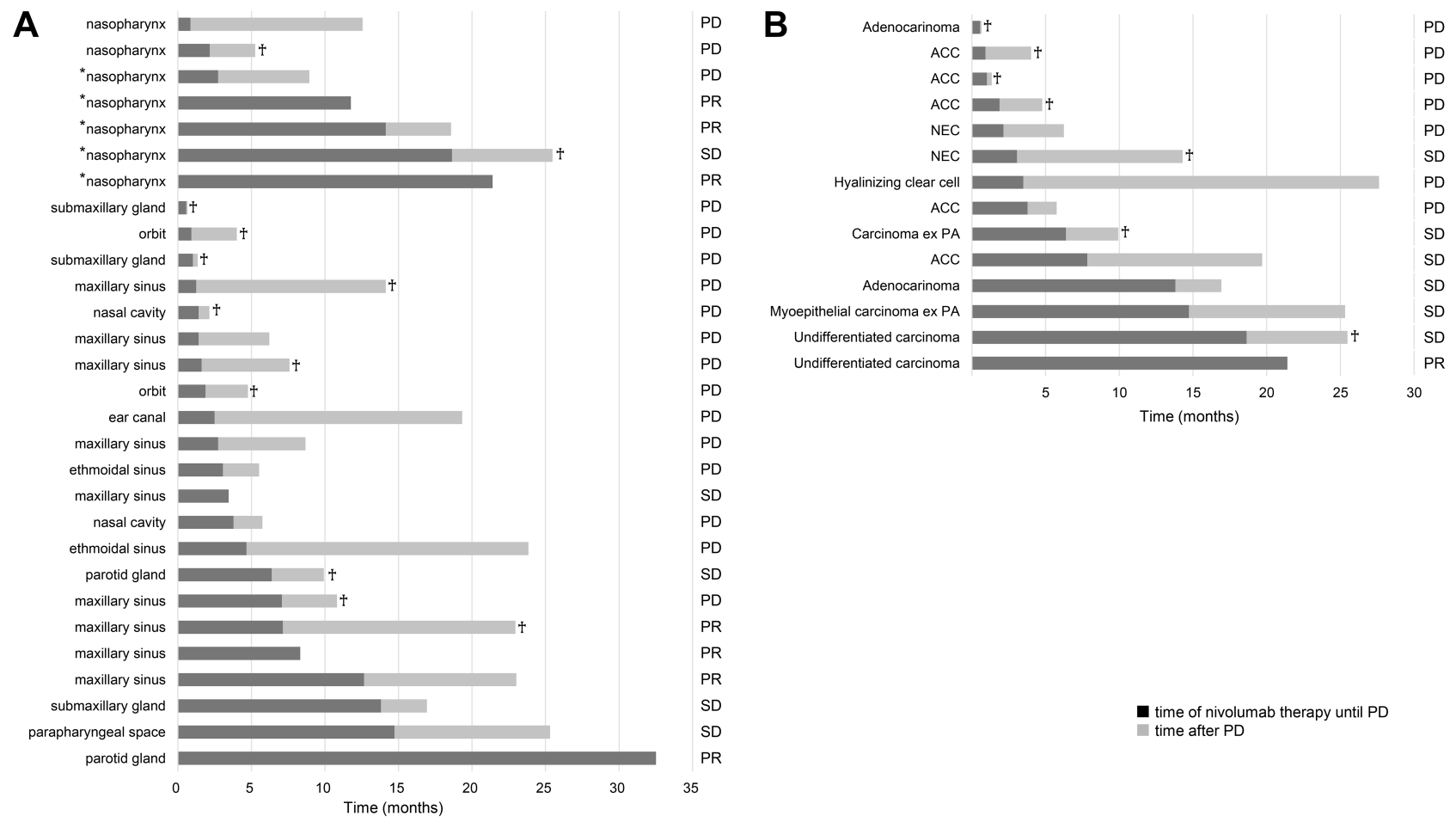

Figure 3 Bar charts showing the duration of nivolumab until progression (black bars) and survival following progression (gray bars) for (A) patients with primary sites excluded from the CheckMate-I4I trial and (B) patients with histological subtypes excluded from the CheckMate- $|4|$ trial.

Notes: + , decreased; *, EBER (Epstein-Barr virus encoded small nuclear RNA) positive.

Abbreviations: ACC, adenoid cystic carcinoma; NEC, neuroendocrine cell carcinoma; PA, pleomorphic adenoma; PR, partial response; SD, stable disease; PD, progressive disease. 
a rationale to the clinician to recommend anti-PD-1 therapy to these patients. These data are consistent with the results of the NCI-9742 trial of nivolumab for patients with nasopharyngeal cancer, which reported survival outcomes comparable to historical data. ${ }^{4}$ However, the differences did not reach the level of statistical significance, which was most likely due to the small sample size.

Some published case series have suggested that nivolumab confers a survival benefit on patients with HNC with rare primary sites. ${ }^{6}$ However, our study found no significant difference between the survival outcomes of patients with HNC in other primary sites than larynx, oral cavity, and pharynx, which suggests that even patients with rare HNC sites might benefit from nivolumab treatment.

In the present study, the survival outcomes were also comparable between nivolumab-treated patients with HNC of SCC and non-SCC (excluded in the CheckMate-141 trial). However, only 1 out of 14 non-SCC patients had a response (7\%); and especially survivals of patients with adenoid cystic carcinoma and neuroendocrine cell carcinoma were shorter. On the other hands, survivals of patients with undifferentiated carcinoma appeared good. On the basis of these data, it would be premature to come to the conclusion that anti-PD-1 therapy provides a similar benefit to non-SCC HNC patients; further research is warranted in these patients.

Nivolumab is now a standard approved therapy for $\mathrm{HNC}$, making it difficult to justify a prospective trial comparing nivolumab efficacy in patients with primary sites and/or histological subtypes excluded from the CheckMate-141 trial. Therefore, the present study provides valuable real-world data in HNC patient groups not studied in interventional clinical trials and our findings support the use of nivolumab treatment for such patients in clinical practice.

Recently, the phase 3 KEYNOTE-048 trial demonstrated that pembrolizumab, an anti-human PD-1 monoclonal antibody, monotherapy or combination therapy with platinum based chemotherapy were appropriate first-line treatments for PD-L1-positive untreated recurrent or metastatic HNC. ${ }^{8}$ In this study, the inclusion criteria were also restricted to patients with SCC of the oropharynx, hypopharynx, larynx, and oral cavity in common with the CheckMate-141 trial. Our findings might provide a potential rationale for pembrolizumab treatments for HNC patients with rare primary sites in clinical practice.
In this study, we did not examine tumor PD-L1 expression because it is not approved as a companion diagnostic test by the Japanese MHLW. Immunohistochemical analysis demonstrated that $44 \%$ of patients in the CheckMate141 trial $^{3}$ and $40 \%$ of patients in the NCI-9742 trial (nasopharyngeal cancer) ${ }^{4}$ were positive for tumor PD-L1 expression (defined as $\geq 1 \%$ of cells with positive staining). Another study reported that $17 \%$ of 167 patients with salivary gland cancer were positive for tumor PD-L1 expression. ${ }^{7}$ However, little is known about tumor PD-L1 expression in $\mathrm{HNC}$ with rare primary locations and it will be of interest to determine whether nivolumab efficacy correlates with tumor PD-L1 expression in these patients. We plan to evaluate this in the patient subgroups described here.

Several limitations of this study should be acknowledged. First, this was a retrospective study with a small number of patients and selection bias may have resulted from physician subjectivity in deciding which patients should receive nivolumab. Second, there were significant differences in patients' baseline characteristics among groups, especially in sex and smoking status. These may be biologically plausible. Chronic tobacco use is the most important risk factor for cancers of the oral cavity, oropharynx, hypopharynx, and larynx (CheckMate-141included sites), however it is not a major risk factor for HNC with other primary sites. And men overwhelmingly use tobacco more than women. Third, the observation time was short, mainly because nivolumab was approved for recurrent or metastatic HNC in Japan less than 3 years ago. We plan to continue accumulating data for a larger number of $\mathrm{HNC}$ patients so that nivolumab treatment efficacy can be analyzed over a longer period.

\section{Conclusion}

This retrospective study evaluated the efficacy of nivolumab for patients with HNC subtypes and primary sites excluded from the CheckMate-141 trial. We found that the response rates and survival outcomes for patients with rare $\mathrm{HNC}$ subtypes and primary site locations were comparable to those obtained in the CheckMate-141 trial, although further research is warranted especially for nonSCC HNC patients.

\section{Abbreviations}

SCC, Squamous cell carcinoma; HNC, Head and neck cancer; PD-1, Programmed death-1; PD-L1, Programmed death-1 ligand; OS, Overall survival; MHLW, Ministry of 
Health, Labour and Welfare; PFS, Progression-free survival; CR, Complete response; PR, Partial response; SD, Stable disease; PD, Progressive disease; RR, Response rate; DCR, Disease control rate.

\section{Ethics Approval and Informed Consent}

Because the data were reported anonymously, the requirement for informed consent was waived. The study was approved by the Institutional Review Board of the Cancer Institute Hospital.

\section{Acknowledgments}

We thank the medical staff of the Department of Head and Neck Surgery, Cancer Institute Hospital, Japanese Foundation for Cancer Research for their support during this study. We thank Anne M. O'Rourke, PhD, from Edanz Group for editing a draft of this manuscript. The abstract of this paper was presented at the 16th Annual Meeting of Japanese Society of Medical Oncology as a poster presentation with interim findings. The poster's abstract was not published.

\section{Author Contributions}

All authors made substantial contributions to conception and design, acquisition of data, analysis and interpretation of data, drafting the manuscript, revising the manuscript critically, read and approve the final draft of the manuscript for submission, gave final approval of the manuscript version to be published and agreed to be accountable for every step of the work.

\section{Funding}

This work was not supported by external funding.

\section{Disclosure}

Dr Yasuyoshi Sato reports personal fees from ONO Pharmaceutical Co., Ltd., Bristol-Myers Squibb Company, MSD K.K., TAIHO Pharmaceutical Co., Ltd., outside the submitted work. Dr Shunji Takahashi reports grants, personal fees from ONO Pharmaceutica and Bristol-Myers Squibb, during the conduct of the study; grants, personal fees from MSD, AstraZeneca, Chugai, and BAYER, outside the submitted work. The authors report no other conflicts of interest in this work.

\section{References}

1. Topalian SL, Drake CG, Pardoll DM. Immune checkpoint blockade: a common denominator approach to cancer therapy. Cancer Cell. 2015;27(4):450-461. doi:10.1016/j.ccell.2015.03.001

2. Postow MA, Callahan MK, Wolchok JD. Immune checkpoint blockade in cancer therapy. J Clin Oncol. 2015;33(17):1974-1982. doi:10.1200/ JCO.2014.59.4358

3. Ferris RL, Blumenschein G, Fayette J, et al. Nivolumab vs investigator's choice in recurrent or metastatic squamous cell carcinoma of the head and neck: 2-year long-term survival update of CheckMate 141 with analyses by tumor PD-L1 expression. Oral Oncol. 2018;81 (April):45-51. doi:10.1016/j.oraloncology.2018.04.008

4. Ma BBY, Lim W-T-T, Goh B-C-C, et al. Antitumor activity of nivolumab in recurrent and metastatic nasopharyngeal carcinoma: an international, multicenter study of the mayo clinic phase 2 consortium (NCI-9742). J Clin Oncol. 2018;36(14):1412-1418. doi:10.1200/ JCO.2017.77.0388

5. Eisenhauer EA, Therasse P, Bogaerts J, et al. New response evaluation criteria in solid tumours: revised RECIST guideline (version 1.1). Eur $J$ Cancer. 2009;45(2):228-247. doi:10.1016/j.ejca.2008.10.026

6. Kokkali S, Ntokou A, Drizou M, et al. Nivolumab in patients with rare head and neck carcinomas: a single center's experience. Oral Oncol. 2019;(May):1-2. doi:10.1016/j.oraloncology.2019.07.002

7. Vital D, Ikenberg K, Moch H, Rössle M, Huber GF. The expression of PD-L1 in salivary gland carcinomas. Sci Rep. 2019;9(1):1-9. doi:10.1038/s41598-019-49215-9

8. Burtness B, Harrington KJ, Greil R, et al. Pembrolizumab alone or with chemotherapy versus cetuximab with chemotherapy for recurrent or metastatic squamous cell carcinoma of the head and neck (KEYNOTE-048): a randomised, open-label, phase 3 study. Lancet (London, England). 2019;394(10212):1915-1928. doi:10.1016/S01406736(19)32591-7
Cancer Management and Research is an international, peer-reviewed open access journal focusing on cancer research and the optimal use of preventative and integrated treatment interventions to achieve improved outcomes, enhanced survival and quality of life for the cancer patient.
The manuscript management system is completely online and includes a very quick and fair peer-review system, which is all easy to use. Visit http://www.dovepress.com/testimonials.php to read real quotes from published authors. 